\title{
A Pilot Study on Zinc Levels in Patients with Rheumatoid Arthritis
}

\author{
Artur Mierzecki • Dorota Strecker • \\ Krystyna Radomska
}

Received: 23 November 2010 / Accepted: 28 December 2010 /

Published online: 29 January 2011

(C) The Author(s) 2011. This article is published with open access at Springerlink.com

\begin{abstract}
The aim of the study was to evaluate zinc levels in three biological compartments (serum, erythrocytes and hair) in patients with rheumatoid arthritis (RA) as compared to healthy individuals. Zinc levels in serum, erythrocytes and hair (in 74 patients with RA and 30 healthy individuals) were assessed by atomic absorption spectroscopy. The mean hair zinc content was significantly lower in RA patients as compared to healthy individuals $(p<$ 0.001). Moreover, a positive correlation was observed in the RA patient group between the erythrocyte zinc levels and the prednisone dose $\left(r_{\mathrm{s}}=0.48, p<0.05\right)$, and a negative correlation was found in this population between the serum zinc levels and disease duration $\left(r_{\mathrm{s}}=-0.42, p<0.0006\right)$. In conclusion, it seems that hair may be a useful complementary study material for evaluating "zinc status" in rheumatoid arthritis patients.
\end{abstract}

Keywords Rheumatoid arthritis $\cdot$ Zinc $\cdot$ Serum $\cdot$ Erythrocytes $\cdot$ Hair

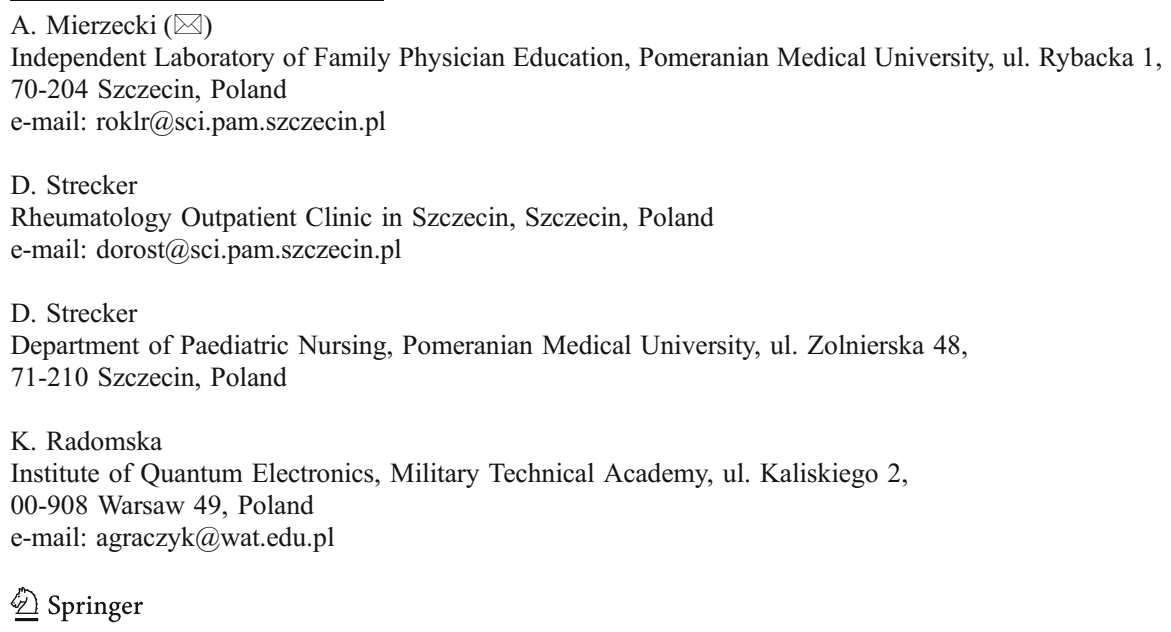




\section{Introduction}

Rheumatoid arthritis (RA) is a well-studied progressive autoimmune disease. However, no factor responsible for the immune system activation in the course of the disease has been identified to date [1]. Among the many contributing agents that have been proposed to take part in the pathogenesis of this condition, trace elements, including zinc, have also been investigated [2-5]. The evidence for their involvement stems from the observation that postmenopausal women consuming higher amounts of zinc are at a lower risk of RA $(\mathrm{RR}=$ $0.39,95 \% \mathrm{CI}=0.17-0.88, p<0.03)[6]$.

It has been shown that reactive oxygen species play a role in the aetiology of RA [1, 610] and that one of them is the superoxide radical, which is eliminated by superoxide dismutase - an enzyme containing zinc in its molecule $[3,5,11]$. It has also been found that over $90 \%$ of this trace element present in erythrocytes is bound with carbonic anhydrase and superoxide dismutase [12]. Furthermore, zinc mobilises vitamin A, a potent antioxidant, from the liver, thus maintaining its proper levels in the blood [11].

Zinc is crucial for the proper functioning of approximately 300 hormones and enzymes in the human body $[11,12]$, the latter representing all the classes taking part in the synthesis and degradation of proteins, carbohydrates, fats and nucleic acids. Zinc constitutes a structural element of alkaline phosphatase (ALP), with four of its atoms being present in the enzyme. Zinc also stimulates ALP synthesis in osteoblasts and plays an important role in bone mineralisation [13]. In addition, zinc is responsible for the latency of metalloproteinases (such as collagenases, gelatinases, stromelysins, matrilysin, metalloelastases and membrane metalloproteinases) by means of a coordination bond between a zinc atom in the centre of the enzyme and a free cysteine-SH group present in the pro-peptide. Notably, the breaking of this bond and the release of the pro-peptide result in the activation of metalloproteinases responsible for articular cartilage destruction observed in RA [11, 12, 14].

Zinc deficiency has been previously studied in an experimental human model involving males on a low-zinc diet (mild zinc deficiency) [15]. The reported effects included lowered plasma testosterone levels, oligozoospermia, decreased natural killer cell function, reduced interleukin 2 production, low thymulin levels, hyperammonaemia, diminished sensitivity to different tastes, impaired adaptation to the dark and decreased lean body mass.

The investigators' opinions on the zinc status in the human body vary, particularly in respect to this element's serum, plasma and erythrocyte levels. Relatively few publications addressing the zinc content in hair are available [16-19], and there seems to be no reports on its assessment in RA patients. Thus, the authors of the present study undertook the task of evaluating the content of this bioelement in serum, erythrocytes as well as hair of patients with rheumatoid arthritis.

The aim of this work was to examine the differences between the levels of zinc present in three fundamental biological compartments in patients with RA and in healthy individuals, with a particular focus on hair.

\section{Material and Methods}

Study Population

Seventy-four patients treated for RA were evaluated in two specialist Rheumatology Outpatient Clinics in Szczecin, Poland. The studied group comprised 20 men and 54 women aged 29-50 (mean age, 39.8 \pm 6.1 years). The diagnosis of RA was based on 
meeting at least four of the seven criteria given by the American College of Rheumatology [20].

RA patients were divided into four subgroups (listed below) depending on the received pharmacological treatment during the previous 6 months prior to the study:

- $\mathrm{MTX}=$ patients treated with methotrexate (MTX) at a weekly dose range from 7.5 to $12.5 \mathrm{mg} /$ week and non-steroidal anti-inflammatory drugs (NSAIDs);

- $\mathrm{MTX}+\mathrm{GC}=$ patients treated as above but also receiving glucocorticoids (GC), prednisone, at a dose of 5.0-12.5 $\mathrm{mg}$ daily;

- $\mathrm{MTX}+\mathrm{GC}+\mathrm{Ca}+\mathrm{D}_{3}=$ patients treated as above but also receiving calcium and vitamin $\mathrm{D}_{3}$ (as means of preventing osteoporosis); and

- $\mathrm{SAS}=$ patients receiving sulphasalazine $(\mathrm{SAS})$ at a dose of $1,500-2,000 \mathrm{mg} /$ daily and NSAIDs only.

The control group consisted of 30 healthy individuals reporting successively to the clinic of two general practitioners in Szczecin for reasons unrelated to RA. This group comprised 8 men and 22 women aged $27-50$ (mean age, 38.2 \pm 8.3 years).

The inclusion criteria applied to both groups were as follows:

1. No diuretics, hypotensive agents, anticonvulsants, antibiotics, vitamin supplements containing studied elements or oral contraceptives (females) taken for at least 6 months prior to the study;

2. Nutrition-following a normal diet;

3. No evident gastrointestinal or urinary disturbances or endocrine conditions;

4. Age below 50 and regular menstruation (females); and

5. Informed consent to take part in the study.

\section{Study Design}

All study participants had their medical history taken and underwent a physical examination and had their zinc levels measured: in the extracellular fluid (serum) and in the intracellular compartment (erythrocytes and hair).

The study has been accepted by the Bioethical Commission (Ethics Board) of the Pomeranian Medical University in Szczecin for studies in human subjects.

Written informed consent was obtained from all patients from both study and control groups.

Biochemical Analysis

Serum and Erythrocyte Zinc Levels

Zinc levels in serum and in erythrocytes were measured by atomic absorption spectroscopy (AAS) using either an acetylene-air or acetylene-nitrous oxide flame. The serum and erythrocyte samples were prepared by mineralisation in a 5:2 mixture of ultrapure nitric acid and perchloric acid until achieving complete destruction of the organic matrix. Next, the solution was transferred quantitatively into a volumetric flask and filled up to the final volume with deionised water.

\section{Hair Zinc Content}

Hair sections of 3-4 cm in length, measured from the skin, were collected from six to eight scalp regions with stainless steel scissors to avoid contamination with other heavy metals. 
The total hair sample weight was $0.2-0.3 \mathrm{~g}$. For at least 6 months prior to the study, no hair treatment was applied that might potentially alter the biological hair content of the studied bioelements (the hair was not dyed, permanent waved, conditioned, etc.). The hair samples were washed with a water solution of non-metal detergent, rinsed with deionised water and dried at $60^{\circ} \mathrm{C}$. Next, they were rewashed with a mixture of anhydrous alcohol and acetone for $25 \mathrm{~min}$, dried at $60^{\circ} \mathrm{C}$ and placed in a desiccator for $24 \mathrm{~h}$. Subsequently, the hair samples were weighed using analytical scales and subjected to mineralisation with a mixture of ultrapure concentrated nitric acid and perchloric acid at a ratio of 5:2 $(\mathrm{v} / \mathrm{v})$. The mineralisation process was conducted at the boiling point of the acid mixture, with water and excess acids being distilled off to approximately one third of the original sample volume. The remaining solution was transferred quantitatively to $25-\mathrm{cm}^{3}$ glass flasks and filled to volume with water distilled three times with a quartz distillation apparatus [23]. The zinc content was assessed by AAS using either an acetylene-air or acetylene-nitrous oxide flame. The measurements were conducted with a Pay-Unicam SP-9 spectrophotometer interfaced with a computer.

The levels of zinc in serum, erythrocytes and hair were analysed at the Institute of Quantum Electronics, Military Technical Academy, Warsaw, Poland.

\section{Statistical Analysis}

Statistical analysis was performed using the StatSoft Polska v. 9.0 package (StatSoft Inc., Tulsa, Oklahoma, USA).

The distribution type of the studied parameters within the analysed groups was determined based on the Shapiro-Wilk test for normality $(N)$, sample size $(n)$, range of values (range), median (Me), mean $(\bar{x})$ and standard deviation (SD). The results from two independent groups were compared using the Student's $t$ test (when the distribution of a given parameter was not significantly different statistically from the normal distribution in any of the comparison groups) or the Mann-Whitney $U$ test (when the distribution of a given parameter was significantly different statistically from the normal distribution in at least one of the groups being compared).

In order to determine a statistical relationship between two variables, either the Pearson's (linear) correlation coefficient (when both variables had normal distribution) or Spearman's rank correlation coefficient (with at least one variable not having the normal distribution) were used.

In all comparisons, the adopted significance threshold was $p$ value $\leq 0.05$.

\section{Results}

Table 1 shows the distribution patterns of the quantitative parameters in RA patients: mean disease duration, RA clinical activity such as the Ritchie articular index for joint tenderness [21] as well as the subjective joint pain score based on the visual analogue scale (VAS), and haematology test results for erythrocyte sedimentation rate (ESR) and haemoglobin $(\mathrm{Hb})$ level. Additionally, the disease activity of RA was determined with the disease activity score including 28 joints using ESR (DAS28-ESR) [22].

Table 2 presents the comparison of zinc levels in serum, erythrocytes and hair from patients with RA and from healthy individuals. Statistically significant lower zinc levels were found in RA patients versus control group, but only for the hair compartment $(p<0.001)$. 
Table 1 Study group characteristics (patients with RA, $n=74$ )

\begin{tabular}{lccrc}
\hline Parameter & Normality of distribution & Range & Median & Mean \pm SD \\
\hline Mean disease duration (years) & - & $1.0-28.0$ & 7.7 & $8.5 \pm 6.7$ \\
Ritchie articular index (points) & - & $2.0-19.0$ & 8.1 & $8.2 \pm 3.4$ \\
VAS (cm) & - & $2.0-8.5$ & 5.2 & $5.1 \pm 1.7$ \\
ESR (mm/h) & - & $2.0-93.0$ & 31.2 & $37.2 \pm 25.1$ \\
$\mathrm{Hb}(\mathrm{g} / \mathrm{dL})$ & + & $10.5-15.1$ & 12.7 & $12.8 \pm 0.9$ \\
$\mathrm{DAS} 28$ & - & $2.6-6.5$ & 5.1 & $4.9 \pm 0.9$ \\
\hline
\end{tabular}

Within the RA patient group, no statistically significant differences were found in the zinc levels between the treatment subgroups irrespective of the evaluated biological compartment (Table 3).

Table 4 presents the values of Spearman's rank correlation coefficients $\left(r_{\mathrm{s}}\right)$ for statistical dependence between the zinc levels in studied biological compartments and the doses of administered MTX and prednisone (GC). A positive correlation was observed between the erythrocyte zinc levels and the glucocorticoid dose $\left(r_{\mathrm{s}}=0.48, p<0.05\right)$.

Table 5 presents the relationship between the evaluated parameters and the levels of zinc in each of the biological compartments. The only statistically significant correlation (a negative one) was observed between the serum zinc levels and the disease duration $\left(r_{\mathrm{s}}=-0.42, p<\right.$ 0.0006). No correlation was established between the zinc levels in the analysed biological compartments and disease activity determined by DAS28.

\section{Discussion}

Our evaluation of the zinc content in the hair of patients with RA is a pioneering study on "zinc status" in RA patients. The available literature offers reports focussing solely on the examination of zinc levels in plasma/serum, urine and, rarely, in erythrocytes of patients with RA [2, 24-29]. The hair is a practical material for conducting bioelement analysis since, similar to skin, myocardium and skeletal muscles, it constitutes a more stable depot of elements than blood serum or erythrocytes $[11,16,17,19,23]$. Growing at a rate of 1.0$2.0 \mathrm{~cm}$ per month, hair along its entire length constitutes a specific reflection of all the biochemical events occurring in the body $[17,18]$. Unlike tissues, hair is the end metabolic product, with various elements incorporated into its composition as it grows. Upon reaching the skin surface, the hair hardens and keratinises, and the elements accumulated during its formation become embedded in its protein structure [17]. The present study demonstrates

Table 2 Comparison of mean zinc levels in serum, erythrocytes and hair of patients with RA versus the control group

\begin{tabular}{lccc}
$\begin{array}{l}\text { Type of sample in which mean zinc } \\
\text { levels/content were assessed }\end{array}$ & RA patients $(n=74)$ & Control group $(n=30)$ & $p$ value \\
\hline Serum $(\mu \mathrm{g} / \mathrm{dL})$ & $80.1 \pm 12.5$ & $72.0 \pm 8.0$ & NS \\
Erythrocytes $(\mu \mathrm{g} / \mathrm{dL})$ & $968.2 \pm 113.9$ & $1008.9 \pm 46.9$ & NS \\
Hair $(\mu \mathrm{g} / \mathrm{g}$ d.h.m.) & $160.9 \pm 27.4$ & $190.8 \pm 29.9$ & $<0.001$
\end{tabular}

d.h.m. dry hair mass 
Table 3 Comparison of mean zinc levels in patients with RA depending on the pharmacological treatment used

\begin{tabular}{llllll}
\hline $\begin{array}{l}\text { Type of sample in which mean } \\
\text { zinc levels/content were assessed }\end{array}$ & \multicolumn{2}{l}{ Treatment regimen } & & $p$ value \\
\cline { 2 - 5 } & $\begin{array}{l}\text { MTX } \\
(n=19)\end{array}$ & $\begin{array}{l}\text { MTX+GC } \\
(n=17)\end{array}$ & $\begin{array}{l}\text { MTX+GC+Ca+D } \\
(n=20)\end{array}$ & $\begin{array}{l}\text { SAS } \\
(n=18)\end{array}$ \\
\hline Serum $(\mu \mathrm{g} / \mathrm{dL})$ & $84.1 \pm 18.2$ & $80.7 \pm 11.9$ & $78.8 \pm 8.2$ & $76.9 \pm 11.5$ & NS \\
Erythrocytes $(\mu \mathrm{g} / \mathrm{dL})$ & $976.3 \pm 131.4$ & $953.2 \pm 101.9$ & $965.4 \pm 122.6$ & $977.1 \pm 99.8$ & NS \\
Hair $(\mu \mathrm{g} / \mathrm{g}$ d.h.m.) & $146.9 \pm 40.9$ & $153.4 \pm 13.1$ & $163.7 \pm 25.8$ & $179.7 \pm 29.7$ & NS \\
\hline
\end{tabular}

$M T X$ methotrexate, $G C$ prednisone, $C a$ calcium, $D_{3}$ vitamin $\mathrm{D}_{3}, S A S$ sulphasalazine, d.h.m. dry hair mass

that the hair zinc content in RA patients is significantly lower than that in healthy individuals and is not dependent on the applied treatment regimen. It therefore seems that the evaluation of the zinc content in hair could be a useful complementary diagnostic method to determine "zinc status" in rheumatoid arthritis patients. Moreover, the fact that this particular evaluation method is completely noninvasive is of significance.

The serum zinc level was also examined in the present study, following on from the fact that it is the standard test for assessing the status of this element in the body. It was demonstrated here, as by other authors previously [28, 29], that RA patients' zinc levels in this particular biological compartment are higher, albeit not statistically significantly, than those in healthy individuals. This is surprising as the levels of this element in rheumatoid arthritis should presumably be decreased, considering the fact that the pro-inflammatory cytokines (IL-1 and TNF- $\alpha$ ) [28] involved in the pathogenesis of this condition inhibit the synthesis of albumins in the liver and decrease their zinc-binding capacity, which in turn should lead to lower levels of plasma zinc [11]. Zoli et al. [5] have demonstrated this in their studies, showing a negative correlation between the levels of IL- $1 \beta$ and TNF- $\alpha$ and zinc levels. The authors have argued that the observed association results from the accumulation of zinc in the liver and inflamed joints caused by elevated IL-1 $\beta$. It seems plausible that the lack of consistency in the available reported data may be due to the rapidly changing plasma zinc levels influenced by such factors as diet, disease activity, pharmacological therapy (e.g. the use of antibiotics, laxatives, diuretics, sedatives, hypnotics and anticonvulsants) [24, 30]. Notably, oral contraceptives may also cause a decrease in plasma zinc levels [12]. However, the present study did not show any association between the level of zinc in patient's serum and the type of applied pharmacological treatment, although a negative, highly statistically significant correlation

Table 4 Correlation between the levels of zinc in serum, erythrocytes and hair and the doses of MTX or prednisone (GC)

Type of sample in which mean zinc levels/content were assessed Spearman's rank correlation coefficient

\begin{tabular}{lcc} 
& MTX $(n=56)$ & GC $(n=37)$ \\
\hline Serum $(\mu \mathrm{g} / \mathrm{dL})$ & 0.14 & 0.04 \\
Erythrocytes $(\mu \mathrm{g} / \mathrm{dL})$ & 0.33 & $0.48^{*}$ \\
Hair $(\mu \mathrm{g} / \mathrm{g}$ d.h.m.) & 0.40 & -0.27 \\
\hline
\end{tabular}

d.h.m. dry hair mass

$* p<0.05$ 
Table 5 Values of Spearman's rank correlation coefficients $\left(r_{\mathrm{s}}\right)$ or Pearson's (linear) correlation coefficients $(r)$ and levels of significance ( $p$ values) for the studied parameters in the group of patients with RA

\begin{tabular}{lccc} 
Correlated parameters & \multicolumn{2}{c}{ Type of sample in which mean zinc levels were assessed } \\
\cline { 2 - 4 } & Serum $(\mu \mathrm{g} / \mathrm{dL})$ & Erythrocytes $(\mu \mathrm{g} / \mathrm{dL})$ & Hair $(\mu \mathrm{g} / \mathrm{g} \mathrm{d}$ d.h.m. $)$ \\
\hline Subject age (years) & $r_{\mathrm{s}}=-0.23$ & $r_{\mathrm{s}}=-0.02$ & $r_{\mathrm{s}}=-0.03$ \\
Mean disease duration (years) & $r_{\mathrm{s}}=-0.42^{*}$ & $r_{\mathrm{s}}=0.09$ & $r_{\mathrm{s}}=-0.01$ \\
Ritchie articular coefficient (score) & $r_{\mathrm{s}}=-0.11$ & $r_{\mathrm{s}}=0.20$ & $r_{\mathrm{s}}=-0.26$ \\
VAS $(\mathrm{cm})$ & $r_{\mathrm{s}}=0.12$ & $r_{\mathrm{s}}=0.07$ & $r_{\mathrm{s}}=-0.26$ \\
ESR $(\mathrm{mm} / \mathrm{h})$ & $r_{\mathrm{s}}=0.03$ & $r_{\mathrm{s}}=0.24$ & $r_{\mathrm{s}}=0.08$ \\
Hb $(\mathrm{g} / \mathrm{dL})$ & $r=-0.17$ & $r=0.03$ & $r=-0.21$ \\
DAS28 & $r_{\mathrm{s}}=0.02$ & $r_{\mathrm{s}}=0.33$ & $r_{\mathrm{s}}=-0.08$
\end{tabular}

d.h.m. dry hair mass

$* p<0.0006$

between the serum zinc levels and the disease duration was observed. The latter is consistent with findings reported by Çaglayan and Sükrü Aydog [25], suggesting that such an effect may be partly due to secondary eating disorders often observed in chronic inflammatory conditions.

There is a considerable amount of data demonstrating that plasma zinc constitutes $<1 \%$ of its total content in the body, with approximately $99 \%$ of this bioelement being located intracellularly [12]. Taking this into consideration, the assessment of zinc level in erythrocytes was also performed since these cells represent a more stable pool than serum and plasma [3, $26,27]$. Therefore, the examination of zinc levels in this biological compartment was performed in the present study as well. The obtained results indicated that the erythrocyte zinc levels might be lower in RA patients as compared to healthy individuals, but this difference was not statistically significant. The small number of publications on zinc concentrations in erythrocytes of RA patients provide inconsistent data, showing either higher $[3,26]$ or lower levels [27] in comparison to control groups. Over $90 \%$ of zinc contained in red blood cells is bound with superoxide dismutase and carbonic anhydrase [12]. Tuncer et al. [3] have reported an increased activity of superoxide dismutase in the erythrocytes of RA patients. The results obtained in the present study may reflect intensified utilisation of zinc by red blood cells. On the other hand, animal studies have demonstrated an increased fragility of erythrocytes due to low zinc content in their cell membranes [12]. This might lead to a leakage of the intra-erythrocyte zinc pool into the extracellular space - an effect that could be the underlying cause of the results obtained in the present study.

The positive correlation found in the present study between the dose of glucocorticoid and erythrocyte zinc level may result from glucocorticoid action, the reduction and consequent inactivation of active oxygen forms. Free oxygen radicals are known as lipid peroxidation inductors, and the peroxidation of the lipids changes the structure and function of cell membranes and inactivates cell membrane enzymes [1, 7].

\section{Conclusion}

It seems that the evaluation of zinc content in hair could be a useful complementary diagnostic method to determine "zinc status" in rheumatoid arthritis patients. Still, our 
results should be considered preliminary and no conclusions beyond the experimental study phase should be drawn.

Acknowledgements The study was conducted under the KBN [Polish Scientific Research Committee] grant no. 6 P05B 12620.

Open Access This article is distributed under the terms of the Creative Commons Attribution Noncommercial License which permits any noncommercial use, distribution, and reproduction in any medium, provided the original author(s) and source are credited.

\section{References}

1. Ozkan Y, Yardým-Akaydýn S, Sepici A, Keskin E, Sepici V, Simsek B (2007) Oxidative status in rheumatoid arthritis. Clin Rheumatol 26:64-68

2. Naveh Y, Schapira D, Ravel Y, Geller E, Scharf Y (1997) Zinc metabolism in rheumatoid arthritis: plasma and urinary zinc and relationship to disease activity. J Rheumatol 24:643-646

3. Tuncer S, Kamanli A, Akçil E, Kavas GO, Seckin B, Atay MB (1999) Trace element and magnesium levels and superoxide dismutase activity in rheumatoid arthritis. Biol Trace Elem Res 68:137-142

4. Zimmermann-Górska I (1999) A modern therapeutic approach to rheumatoid arthritis [Współczesne podejście do reumatoidalnego zapalenia stawów]. Alerg Asthma Immunol 4:83-90

5. Zoli A, Altomonte L, Caricchio R et al (1998) Serum zinc and copper in active rheumatoid arthritis: correlation with interleukin $1 \beta$ and tumour necrosis factor $\alpha$. Clin Rheumatol 17:378-382

6. Cerhan JR, Saag KG, Merlino LA, Mikuls TR, Criswell LA (2003) Antioxidant micronutrients and risk of rheumatoid arthritis in a cohort of older women. Am J Epidemiol 157:345-354

7. Sarban S, Kocyigit A, Yazar M, Isikan UE (2005) Plasma total antioxidant capacity, lipid peroxidation, and erythrocyte antioxidant enzyme activities in patients with rheumatoid arthritis and osteoarthritis. Clin Biochem 38:981-986

8. Fautrel B, Bourgeois P (2000) Affections rheumatismales: généralités. Drugs 59(Spec. issue 1):1-9

9. Piotrowska-Jastrzębska J, Mikołuć B, Motkowski R (2002) Nutritional antioxidants in health and disease [Rola antyoksydantów żywieniowych w stanie zdrowia i choroby]. Terapia 10:43-49

10. Sarban S, Isikan UE, Kocabey Y, Kocyigit A (2007) Relationship between synovial fluid and plasma manganese, arginase, and nitric oxide in patients with rheumatoid arthritis. Biol Trace Elem Res 115:97-106

11. Tapiero H, Tew KD (2003) Trace elements in human physiology and pathology: zinc and metallothioneins. Biomed Pharmacother 57:399-411

12. Vallee BL, Falchuk KH (1993) The biochemical basis of zinc physiology. Physiol Rev 73:79-118

13. Heath DA, Shaw NJ (2001) Calcium and bone metabolism. In: Brook C, Hindmarsh P (eds) Clinical pediatric endocrinology, 4th edn. Blackwell Science, Oxford, pp 377-389

14. Wong P, Cuello C, Bertouch JV et al (2000) The effects of pulse methylprednisolone on matrix metalloproteinase and tissue inhibitor of metalloproteinase-1 expression in rheumatoid arthritis. Rheumatology 39:1067-1073

15. Prasad AS (2008) Zinc in human health: effect of zinc on immune cells. Mol Med 14:353-357

16. Dunicz-Sokolowska A, Długaszek M, Radomska K, Wlaźlak E, Surkont G, Graczyk A (2007) Contents of bioelements and toxic metals in the Polish population determined by hair analysis. Part III. Adults aged 20-40 years. Magnes Res 20:43-52

17. Ho J, Boeheim F, Pangborn J, Spitz J, Smith B (2001) Hair element testing: clinical utility and reliability. Great Smokies Diagnostic Laboratory, Asheville

18. Seidel S, Kreutzer R, Smith D, McNeel S, Gillis D (2001) Assessment of commercial laboratories performing hair mineral analysis. JAMA 285:67-72

19. Wang CT, Li YJ, Wang FJ, Shi YM, Lee BT (2008) Correlation between the iron, magnesium, potassium and zinc content in adolescent girls' hair and their academic records. Chang Gung Med J 31:358-363

20. Arnett FC, Edworthy SM, Bloch DA et al (1988) The American Rheumatism Association 1987 revised criteria for the classification of rheumatoid arthritis. Arthritis Rheum 31:315-324

21. Ritchie DM, Boyle JA, McInnes JM et al (1968) Clinical studies with an articular index for the assessment of joint tenderness in patients with rheumatoid arthritis. Q J Med 147:393-406

22. Wells G, Becker JC, Teng J et al (2009) Validation of the 28-joint Disease Activity Score erythrocyte sedimentation rate comparison with the DAS28 based on in patients withrheumatoid arthritis, and C- 
reactive protein against disease progression response criteria based on (DAS28) and European League Against Rheumatism. Ann Rheum Dis 68:954-960

23. Radomska K, Graczyk A, Konarski J (1993) Contents of macro- and microelements in human body determined by hair analysis. Populational studies. Clin Chem Enzym Comms 5:105-118

24. Balogh Z, El-Ghobarey AF, Fell GS, Brown DH, Dunlop J, Dick WC (1980) Plasma zinc and its relationship to clinical symptoms and drug treatment in rheumatoid arthritis. Ann Rheum Dis 39:329-332

25. Çaglayan O, Sükrü Aydog Y (1997) Serum zinc and copper levels in rheumatoid arthritis. J Islamic Acad Sci 10:19-24

26. Dore-Duffy P, Peterson M, Catalanotto F et al (1990) Zinc profiles in rheumatoid arthritis. Clin Exp Rheumatol 8:541-546

27. Milanino R, Frigo A, Bambara LM et al (1993) Copper and zinc status in rheumatoid arthritis: studies of plasma, erythrocytes, and urine, and their relationship to disease activity markers and pharmacological treatment. Clin Exp Rheumatol 11:271-281

28. Yazar M, Sarban S, Kocyigit A, Isikan UE (2005) Synovial fluid and plasma selenium, copper, zinc, and iron concentrations in patients with rheumatoid arthritis and osteoarthritis. Biol Trace Elem Res 106:123-132

29. Szpak A, Szechciński J, Kowalski M (1996) Trace elements in blood serum and joint fluid in rheumatoid arthritis [Pierwiastki śladowe w surowicy krwi i płynie stawowym w reumatoidalnym zapaleniu stawów]. Reumatologia 34:229-233

30. Konarski J, Radomska K, Graczyk A (1993) Zinc its role and functions in metabolic processes of human's organism [Cynk jego rola i funkcje w procesach metabolicznych organizmu człowieka]. Mag Med 4:13-19 